\title{
Malignant melanoma in Jamaica
}

\author{
Alan K. Butler \\ F.R.C.S. \\ Senior Registrar, \\ University College Hospital of the West Indies \\ Kingston 7, Jamaica, W.I.
}

DATA collected from thirty-nine cases of melanoma seen at the University Hospital of the West Indies form the basis of this study. The period under review is 1953 to 1965 .

\section{Clinical features}

There were twenty-three males and sixteen females - this ratio is the reverse of that encountered in other series as reported in an editorial of the Lancet in 1965. The average age of the patients was 52.2 years for males and 52.4 years for females. The age distribution is shown in Fig. 1.

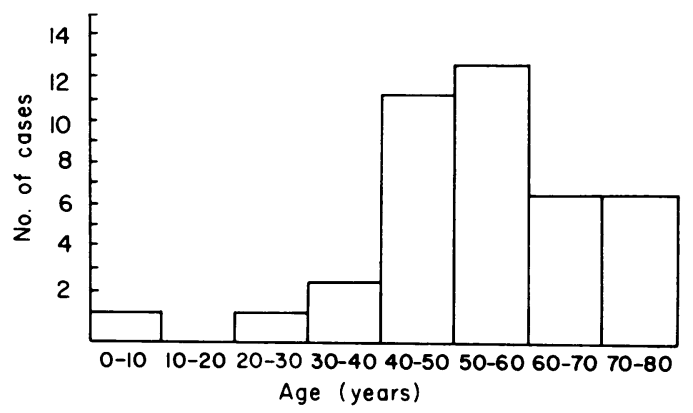

FIG. 1. Age distribution.

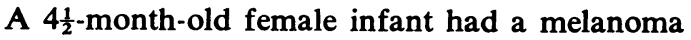
arising in the mucosa overlying the maxilla. Melanoma in infancy is a clinical curiosity. Transplacental transfer of melanoma from mother to foetus has been reviewed by Skov-Jensen, Hastrup \& Lambrethsen (1966). There is no evidence that such was the case here. This lesion in situ, the resected specimen and a photomicrograph of the lesion are shown in Figs. 2, 3 and 4, respectively.
No other case in infancy or childhood was seen. The rarity of truly malignant melanoma in childhood has been appreciated since Allen \& Spitz (1953) described juvenile melanomas.

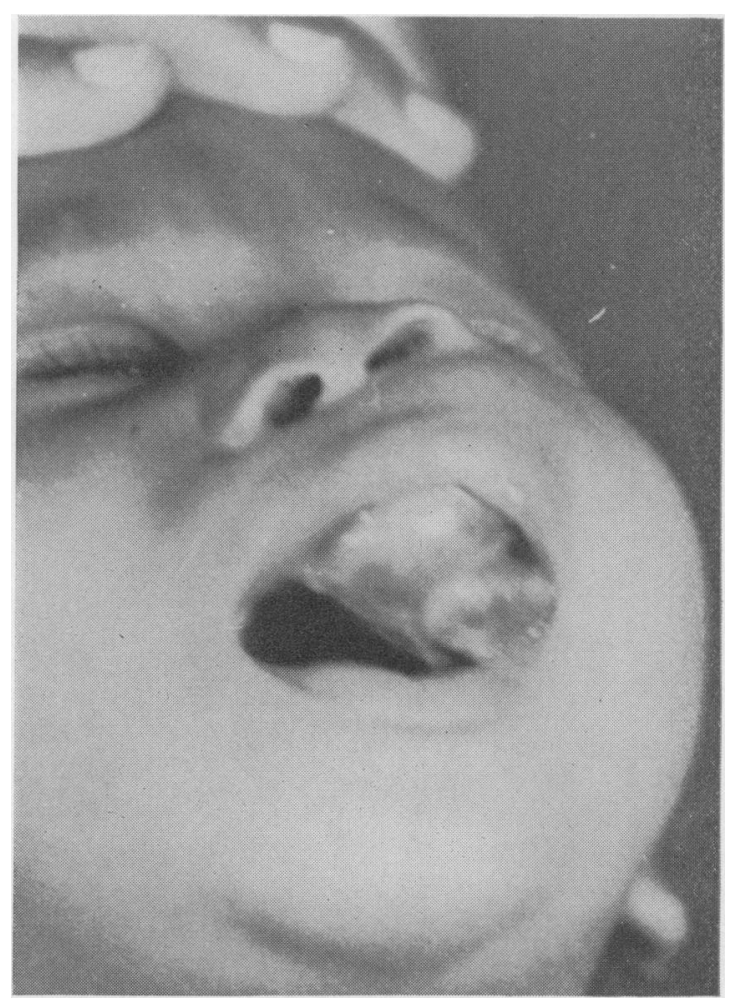

Fig. 2. Melanoma of the mucous membrane of the mouth in an infant of $4 \frac{1}{2}$ months. 


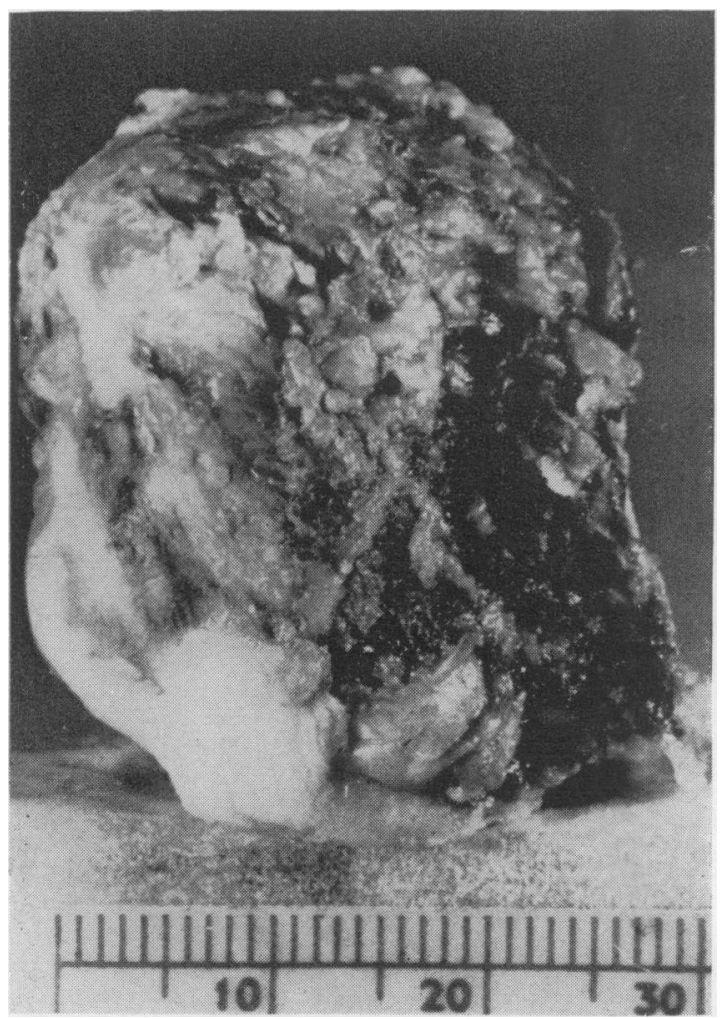

Fig. 3. Resected maxilla from $4 \frac{1}{2}$-month-old infant.

\section{Site of the lesion}

The location of the primary lesion is shown in Table 1. Seventy-seven per cent of lesions occurred on the heel, sole of the foot and toes. Ten patients $(25 \%)$ reported the existence of a previous benign lesion which had been noticed for 2-20 years before a change became apparent. The changes which caused the patient to seek medical advice were increasing pigmentation, 'weeping', tenderness, bleeding, ulceration, infection and pain. In some cases, the ulcer showed a tendency to heal and then break down. Infection was so marked in three patients that antibiotics had been administered and incisions for drainage of pus performed by local practitioners before they came to the hospital. Five patients related the onset of the lesion to remote specific trauma, such as a cut which had healed-the lesion developing at the same site-or prolonged repeated trauma caused by a nail in a boot.

TABLE 1

Location of the primary lesion

\begin{tabular}{lrc}
\hline Location & No. & Percentage \\
\hline Face & 1 & \\
Trunk & 4 & \\
Mucous membrane & 3 & \\
Thigh & 1 & \\
Sole of foot & 25 & 62 \\
Toes & 4 & \\
\hline
\end{tabular}

Fig. 4. Histology: a group of pigmented tumour cells infiltrating soft tissue. H \& E, $\times 165$.

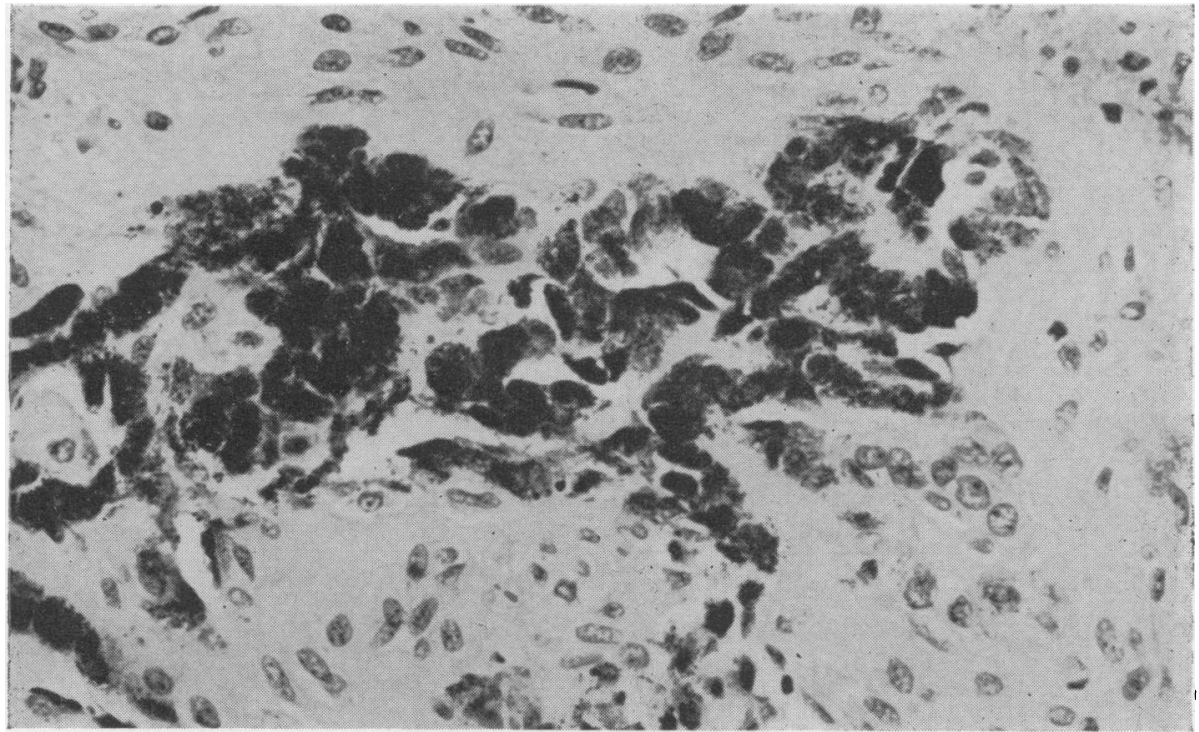




\section{Melanoma of mucous membrane}

A man, aged 77 years, presented with a melanoma of the alveolar margin of the lower jaw and with metastases to lymph nodes in the neck.

One patient had a melanoma of the anal canal - the inguinal nodes not being obviously involved. This was treated by a classical abdomino-perineal excision.

A third case was that of the infant referred to above. This was treated by maxillectomy. This infant died 2 years later but, unfortunately, a post-mortem was not obtained.

\section{Extent of disease when first seen}

This is shown in Table 2. Stage I represents cases in which the disease was clinically localized to the primary site. In Stage II clinically involved nodes were considered resectable. In Stage III the nodes were fixed. Stage IV represents cases in which there were metastases beyond the regional lymph nodes.

TABLE 2

Stage of disease when first seen at U.W.I.

\begin{tabular}{rcc}
\hline Stage & No. of cases & Percentage \\
\hline I & 17 & 44 \\
II & 17 & 44 \\
III & 2 & 5 \\
IV & 2 & 5 \\
Total & 38 & 98 \\
\hline
\end{tabular}

Of the Stage I group only two could be described as superficial melanomata. In every other case the lesion showed one or more of the following features - ulceration, tumour formation, satellitism, gross infection. One patient in the Stage II group had involvement of the popliteal as well as the inguinal group of lymph nodes. The prevalence of these lesions on the heel makes the popliteal fossa an important site for lymph node metastases. Photographs of typical lesions are shown in Fig. 5.

The average duration of symptoms before the patients sought medical advice was $\mathbf{9 \cdot 2}$ months.

\section{Treatment}

The primary lesion

Lesions of the sole of the foot were treated by excision and split-skin grafting eleven times, by below-knee amputation nine times and by a Syme's amputation once. Amputation of one or more toes was performed four times. At other sites, excision and split-skin grafting was the method of choice.

\section{The lymph nodes}

Stage I cases were treated by excision of the primary lesion only, except in three instances when a prophylactic dissection of the nodes was performed, although this was done at a second operation. Stage II cases had a lymph node dissection performed as a separate operation a few

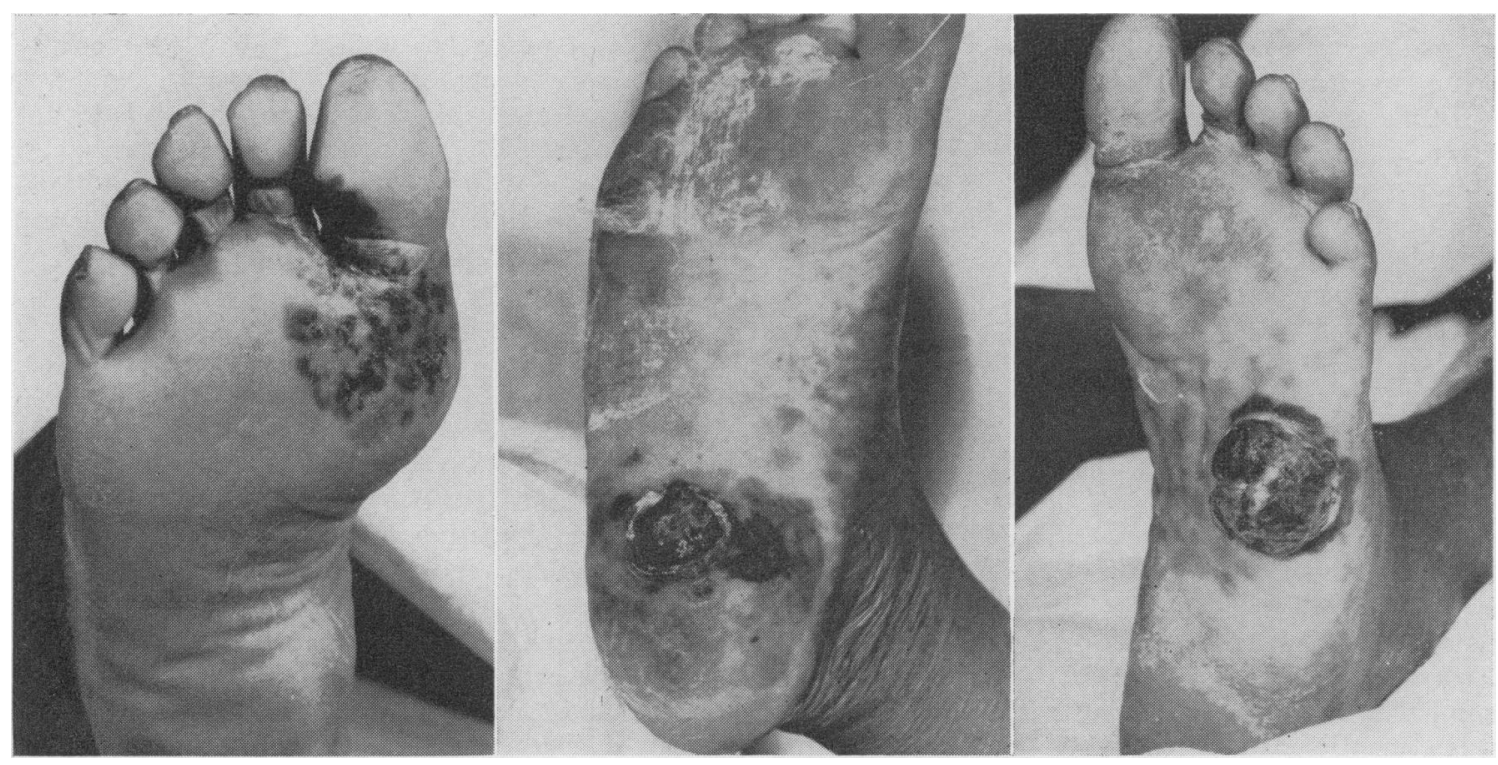

Fig. 5. Malignant melanomata of the sole of the foot showing typical features of ulceration, tumour formation, 'halo' and 'satellites.' 
weeks after the primary lesion was excised, except in one instance when the two operations were performed at the same time. One hind-quarter amputation and one disarticulation through the hip joint were performed for recurrent disease. Radiotherapy and chemotherapy have not been used to date.

\section{Results}

The fate of only eighteen patients $(46 \cdot 2 \%)$ is known. Of these, ten belonged to Stage I, seven to Stage II and one to Stage III. Of the Stage I group, five died after an average survival of 18 months, five are alive and clinically free from disease 1, 1 $\frac{1}{2}, 2,6$ and 6 years, respectively. Of the Stage II group, four died after an average survival of $2 \frac{1}{2}$ years, three are alive after $1,1 \frac{1}{2}$ and 2 years, respectively. Attempts on more than one occasion to trace any of the remaining patients have been completely unsuccessful.

\section{Discussion}

In the U.S.A. malignant melanoma comprises $1.3 \%$ of all cancers. Allen \& Spitz (1953) estimated the probability of malignant melanoma to be $2 \cdot 7$ times higher in the Caucasian than in the Negro. In our predominantly Negro population $(76.8 \%)$, melanoma also comprises $1.3 \%$ of all cancers. Thirteen per cent of all skin cancers in Jamaica are melanoma (Jamaica Cancer Registry) as compared with an estimated figure of $3 \%$ elsewhere (Cade, 1961). All but one of the thirty-nine cases described have occurred in Negroes. The incidence of malignant neoplasms in Jamaica has been discussed by Bras, Walter \& Ashmeade-Dyer (1965).

The enormous predilection of the disease for the sole of the foot is likely to be significant. In this group of patients the figure is $62 \%$. In three collected series among African Negroes, Petersen, Bodenham \& Lloyd (1962) found over $70 \%$ of cases occurring on the leg and foot. In this respect, the role of trauma in the aetiology of melanoma needs to be determined. It is generally agreed that most malignant melanomata develop from preexisting benign pigmented lesions. The junctional naevus, to which group all benign melanomata of the sole of the foot belong, is the lesion which most commonly becomes malignant. Why all 'moles' of the sole of the foot belong to this group is unknown. Trauma is not considered to be important in this transformation by most authorities. Recently, however, Lea (1965), in a statistical comparison of the frequency with which trauma was mentioned in patients with malignant melanoma and others with basal cell carcinoma, found trauma to be a significant factor in the former. Although agreeing that trauma is not important in the aetiology of the disease, most authorities advise that benign lesions that are exposed to repeated trauma should be excised (Lehman, Cross \& de Wayne, 1966).

Once a malignant melanoma has developed, trauma is regarded as a significant factor in the dissemination of the disease and as a potent factor adversely affecting prognosis. With our patients, the problem is two-fold. Many patients traumatize the lesion deliberately in efforts at self-treatment. Others have had the lesion traumatized by their doctors because the true nature was not realized. Simply walking on a melanoma of the sole of the foot might be walking to one's grave.

Any lesion of the sole of the foot which is thought to be malignant should be considered a melanoma until proved otherwise (Ackerman, 1949).

Once the diagnosis is suspected, the management of the primary lesion should be wide excision at the earliest moment. If it is considered that a histological diagnosis is indicated before definitive treatment, this should be done by frozen section. Certainly, to excise a lesion locally and await a report over a period of 2 weeks or more is not justified.

The question has been asked, 'How wide should be a wide excision?' It must be appreciated that it is quite a different matter excising a pigmented lesion not thought to be malignant from excising a malignant melanoma. A benign lesion simply needs to be excised completely. The specimen should always be examined histologically.

In recent reports, attempts have been made to define more accurately the area and depth of tissue which needs to be removed for a malignant lesion. Mundt, Guralnick \& Baker (1965) suggest that a lesion with a diameter of less than $1 \mathrm{~cm}$ should be cleared by a distance of at least $1 \mathrm{~cm}$, and that larger lesions with satellites should be cleared by a distance equal to one or two times the diameter of the entire lesion. Petersen et al. (1962) suggested for larger lesions a 'clearing distance' of from 5 to $15 \mathrm{~cm}$.

It has generally been considered that the deep fascia should always be included, but Mundt et al . (1965), Daland (1959) and Kragh \& Erich (1960) showed that inclusion of the deep fascia did not improve cure or recurrence rates.

In this group of patients, major amputation was performed on a number of occasions for lesions of the sole of the foot because of the extent of the lesions. It should not be forgotten, however, that a split-skin graft functions well on the sole of the foot and the foot need not be sacrificed except for extensive lesions. 


\section{Lymph node dissection}

Recent reports suggest that there is a definite place for prophylactic block dissection (Lancet, 1965; Mundt et al., 1965). The incidence of histologically present metastases in nodes which were clinically negative has been found to be quite high. Several reports show figures varying from $20 \%$ to $60 \%$ (Stehlin et al., 1966). Sir Stanford Cade (1961) did not recommend prophylactic block dissection unless this could be done in continuity with the primary lesion, but he indicated that careful follow-up was then imperative. The high proportion of patients who default from our clinics makes a prophylactic dissection a highly recommendable procedure. It is suggested that the lymph node dissection should be performed 2-3 weeks after the primary lesion has been excised in order to allow lymphatic emboli of tumour cells to reach the nodes, but it remains to be shown that this delay improves prognosis.

\section{Prognosis and outlook}

It is important to appreciate that the prognosis in malignant melanoma is better than was once thought. Five-year cure rates in patients treated for cure have been as high as $50 \%$ (Petersen et al., 1962). A number of factors mitigate against an improvement in the outlook for our patients. Both the site and size of the lesion influence the prognosis, and also especially the first attempt at treatment. The larger the lesion on first attendance the worse the outlook. Some authors have found that the outlook for lesions of the foot is comparatively poor. Trauma to an established lesion is common among our patients and the initial treatment that many patients receive leaves much to be desired.

In recent years, more and more patients with melanoma of an extremity have been subjected to the technique of regional perfusion with chemotherapeutic agents, especially phenylalanine mustard. The method has yielded very satisfying results in a number of cases (Stehlin et al., 1966 ; Creech et al., 1958). The location of the primary lesion on the foot in most of our patients lends itself to the useful exploration of this technique in the initial treatment or later in the event of the development of 'intransit' metastases. Finally, radiotherapy should be considered in the management of advanced cases (Cade, 1961).

\section{Summary}

Malignant melanomas comprise $1.3 \%$ of all cancers in Jamaica and $13 \%$ of all skin cancers. In $62 \%$ of cases the lesion develops on the sole of the foot. Of thirty-nine cases seen at the University Hospital of the West Indies between 1953 and 1965 , there are only two known 5-year survivors. The role of trauma in the aetiology of the disease and its influence on prognosis are discussed. Although melanoma should not be considered a hopeless disease as it has been in the past, local factors tend to influence the outlook in Jamaica adversely.

\section{References}

Ackerman, L.V. (1949) Malignant melanoma of the skin. Clinical and pathological analysis of 75 cases. Cancer. 2 , 175.

Allen, A.C. \& SpITz, S. (1953) Malignant melanoma. A clinico-pathological analysis of the criteria for diagnosis and prognosis. Cancer, 6, 1 .

Bras, G., Walter, D.C. \& Ashmeade-Dyer, A. (1965) Incidence of malignant neoplasms in Jamaica. Brit. J. Cancer, 19, 681.

Cade, S. (1961) Malignant melanoma. Ann. R. Coll. Surg. 28, 331.

Creech, O., Krementz, E.T., Ryan, R.F. \& Winblad, J.N. (1958) Chemotherapy of cancer-regional perfusion utilizing an extra-corporeal circuit. Ann. Surg. 148, 616.

DALAND, E.M. (1959) Malignant melanoma-personal experience with 170 cases. New Engl. J. Med. 260, 453.

KRAGH, L.V. \& ERICH, J.B. (1960) Malignant melanomas of the head and neck. Ann. Surg. 151, 91.

LANCET (1965) Editorial. Lancet, ii, 1171.

LEA, A.J. (1965) Malignant melanoma of the skin. The relationship to trauma. Ann. R. Coll. Surg. 37, 169.

Lehman, J.A., JR, Cross, F.S. \& DeWayne, G.R. (1966) Clinical study of 59 patients with malignant melanoma. Cancer, 19, 611.

Mundt, E.D., Guralnick, E.A. \& Raker, J.W. (1965) Malignant melanoma. A clinical study of 427 cases. Ann. Surg. 162, 15.

Petersen, N.C., Bodenham, D.C. \& Lloyd, M.D. (1962) Malignant melanoma of the skin. A study of origin, development, aetiology, spread, treatment and prognosis. Brit. J. plast. Surg. 15, 49.

Skov-Jensen, T., Hastrup, J. \& Lambrethsen, E. (1966) Malignant melanoma in children. Cancer, 19, 620.

Stehlin, J.S., Leslie-Smith, F., JR, Bao-Shaw Jing, M.D. \& Derrell, S. (1966) Melanoma of the extremities complicated by intransit metastases. Surg. Gynec. Obstet. $122,3$. 